\title{
Dengue infection: An emerging cause of neuromuscular weakness
}

Dengue fever is caused by dengue virus which belongs to the family filoviridae and genus flavi virus. Aedes aegypti is the vector responsible for transmission of the viral infection. Clinical spectrum ranges from an uncomplicated febrile illness to devastating hemorrhages and refractory shock. Hemorrhagic manifestations in dengue hemorrhagic fever (DHF) range from petechial hemorrhages to the life-threatening gastrointestinal, pulmonary, and cerebral or genitourinary hemorrhages.

Neurological manifestations have been increasingly recognized over the last many epidemics. Various neurological involvements reported in dengue virus infection are encephalitis, acute disseminated encephalomyelitis, transverse myelitis, Guillain-Barré syndrome (GBS), myositis, and stroke. ${ }^{[1-8]}$

Though dengue virus has been considered a non neurotropic virus, neuroinvasion has been reported in five fatal cases of dengue encephalopathy in which dengue virus antigen was detected in the brain by immunochemistry. ${ }^{[7]}$ In patients with dengue encephalitis, CSF pleocytosis and positive IgM and polymerase chain reaction (PCR) tests have also been reported, suggesting neuroinvasion.

Neuromuscular complications have been reported in patients with dengue infection. They are GBS, acute quadriparesis due to hypokalemia, and myositis ${ }^{[5,8]}$ Hira et al. in this issue reported 12 patients with different neuromuscular problems such as hypokalemic periodic paralysis, GBS, and myositis. ${ }^{[9]}$ The proposed mechanism of hypokalemia is due to redistribution of potassium in cells or transient renal tubular abnormalities leading to increased urinary potassium wasting. Hypokalemia in dengue fever responds well to potassium correction with complete recovery. ${ }^{[8]}$ Antecedent infection which

\begin{tabular}{|l|l|}
\hline \multicolumn{2}{|c|}{ Access this article online } \\
\hline Quick Response Code: & Website: \\
\hline & www.ruralneuropractice.com \\
\cline { 2 - 2 } & \\
& \\
\hline
\end{tabular}

evokes an immune response which affects the myelin or the axon of peripheral nerves has been elucidated as the mechanism for GBS in these patients. ${ }^{[4]}$ The diagnosis of myositis is based on clinical presentation, raised creatinine phosphokinase (CPK), electromyography (EMG) evidence, and muscle biopsy. Misra et al., reported five patients presenting with acute pure motor weakness with raised CPK. ${ }^{[5]}$ EMG and muscle biopsy were consistent with myositis in one of those patients.

Neurological manifestations in dengue fever are not uncommon. Clinicians should be aware of these manifestations particularly who present with quadriparesis and most of these patients make full recovery.

Jency Koshy, Jeyaraj D Pandian ${ }^{1}$

Departments of Medicine and ${ }^{1}$ Neurology, Christian Medical College, Ludhiana, Punjab, India

Address for correspondence: Dr. Jeyaraj D Pandian, Department of Neurology, Betty Cowan Research and Innovation Centre, Christian Medical College, Ludhiana, Punjab-141 008, India. E-mail: jeyarajpandian@hotmail.com

\section{References}

1. Solomon T, Dung NM, Vaughn DW, Kneen R, Thao LT, Raengsakulrach B, et al. Neurological manifestations of dengue infection. Lancet 2000; 25:1053-9.

2. Gera C, George U. Acute disseminating encephalomyelitis with hemorrhage following dengue. Neurol India 2010;58:595-6.

3. Seet RC, Lim EC, Wilder-Smith EP. Acute transverse myelitis following dengue virus infection J Clin Virol 2006;35:310-2.

4. Santos NQ, Azoubel AC, Lopes AA, Costa G. Bacellar A. Guillain Barre syndrome in the course of dengue: Case report. Arq Neuropsiquiatr 2004;62:144-6.

5. Misra UK, Kalita J, Syam UK, Dhole TN. Neurological manifestations of dengue virus infection. J Neurol Sci 2006;244:117-22.

6. Mathew S, Pandian JD. Stroke in patients with dengue. J Stroke Cerebrovasc Dis 2010;19:253-6.

7. Miagostovich MP, Ramos RG, Nicol AF, Nogueira RM, Cuzzi-Maya T, Oliveira AV, et al. Retrospective study on dengue fatal cases. Clin Neuropathol 1997;16:204-8.

8. Jha S, Ansari MK. Dengue infection causing acute hypokalemic quadriparesis. Neurol India 2010;58:592-4.

9. Hira HS, Kaur A, Shukla A. Acute neuromuscular weakness associated with dengue infection. J Neurosci Rural Pract 2012;3:36-9

How to cite this article: Koshy J, Pandian JD. Dengue infection: An emerging cause of neuromuscular weakness. J Neurosci Rural Pract 2012;3:1. 